\title{
Public Accounts Committee (PAC) Practices and Financial Performance: Analysis of Local Administrative Entities in Rwanda
}

\author{
Mbonigaba Celestin \\ Business and Development Studies, Kibogora Polytechnic, Nyamasheke, Rwanda
}

Email address:

mboncele5@gmail.com

\section{To cite this article:}

Mbonigaba Celestin. Public Accounts Committee (PAC) Practices and Financial Performance: Analysis of Local Administrative Entities in Rwanda. Journal of Finance and Accounting. Special Issue: Financial Inclusion, Accounting Perspectives and Development.

Vol. 7, No. 5, 2019, pp. 153-160. doi: 10.11648/j.jfa.20190705.14

Received: August 19, 2019; Accepted: September 29, 2019; Published: October 20, 2019

\begin{abstract}
The study entitled PAC practices and financial performance: Analysis of local administrative entities in Rwanda was about assessing the contribution of PAC in raising the financial standards of local entities in terms of performance. This study considered the objectives of assess the recommendations raised by PAC based OAG observations in study area, monitoring and evaluating the progressive implementation of PAC and OAG recommendations in study area, weighting the indicators of performance in study area, finding out the correlation between the performance of local administrative entities and recommendations raised by PAC based OAG in study area. The researcher used qualitative and quantitative approaches as the study was descriptive. The considered target population were 23 in period of 2015-2018. The universal population was taken as sample size and the data collection instrument which been used were questionnaires where the data were analyzed using SPSS software. Referring to objective one, it is obvious that; in table 1 the researcher sought to know the recommendations raised by PAC basing on OAG observations and how are being implemented; in fact, it was revealed that PAC involves in regular analysis of OAG report as reported by $69.6 \% \%$ of respondent who agreed to this statement. The second objective revealed that the time of implementation of PAC recommendations based OAG observation and how they are executed; actually, it was revealed that regular time to carry out monthly PFM meeting is planned as strongly reported by 56.5 and agreed by $43.5 \%$ of respondents. The third objective revealed that table 3 the indicators of performance among local administrative entities due to implementation of recommendation raised by PAC; actually, it was revealed that the district performed in, Social, health, agriculture, education, infrastructures and other entities as reported by $100 \%$ of respondent who agreed to this statement; $65.2 \%$ of respondents pointed out that Local administrative entities executed PAC recommendations. This was also supported by R square of 0.787 which implied that the predictor variables (Recommendations raised by PAC and follow up of recommendations) can explain the performance of local administrative entities at $78.7 \%$.
\end{abstract}

Keywords: Public Accounts Committee, Financial Performance, Local Administrative Entities

\section{Introduction}

Globally, over the years, the Association of Public Accounts Committees (APACs) has played a vital role in capacitating PACs members and support staff so that they could effectively and efficiently perform their oversight and accountability functions [1]. Likewise, in Africa, the situation is gradually changing for the better. This is primarily due to the requisite skills and knowledge acquired by members of the PACs when performing oversight responsibilities over the executives. For instance, in the 2009/10 financial year, the Auditor General Limpopo reported that $67 \%$, 25\% and $8 \%$ of the Limpopo Provincial Departments in South Africa audited received unqualified, qualified and disclaimer of opinions respectively [2]. The association annually organizes a conference in order to provide delegates with an opportunity to interact, network, share best practices and experiences with regard to oversight and accountability matters [3]. Burnell, Peter [4] sought to identify possible courses of action to improve outcomes through more effective use of 
PACs. Three main priorities were identified: capacity building - the need to improve the ability of parliaments and their PACs to carry out their functions by being provided with adequate resources, training and access to relevant expertise; independence - that they be free from political or legal constraints that could inhibit them from carrying out their duties diligently; information exchange - that PACs have the means to exchange information and ideas so as to keep them up-to-date with important developments, changing standards and best practices as they emerge.

The PAC operates as a key part of parliament's control over public spending that combines political oversight with technical expertise. The Committee of Public Accounts (PAC) was first established on $8^{\text {th }}$ April 1861 in England [5]. The Committee of Public Accounts, more fashionably called the Public Accounts Committee, was established in 1861 as a" circle of control" during William Gladstone's period as Chancellor of the Exchequer [6]. The committee examined whether or not such decisions and undertakings have been implemented, the extent to which they have been implemented, and whether such implementation has taken place within the minimum time necessary. The committee also looked into whether or not legislation passed by the House has been operationalized the extent to which such operationalization has taken place and within the minimum time necessary [7].

It owes its origins to the earlier appointment of the Commissioners of Public Account in 1780. The appointment of commissioners regularized past practice as parliament was concerned that there should be adequate accounts to show how grants and monies had been paid. The nature of this ex post form of control was the main way of bringing transparency to financial processes that were largely a matter of internal control [8].

The association distinguishes itself as an association concerned with public finance management, empowerment and promotion of sound, accountable and transparent governance in collaboration with oversight committees and other relevant bodies [9].

By the way, to ensure performance of local administrative entities performance, PACs recommendations should be implemented and the follow up must be done. For example, the Kenya National Assembly has established a committee on implementation. Its mandate includes scrutiny of resolutions of the House including adopted committee reports, petitions and the undertakings given by the government on the floor of the House [10].

Normally, this study was designed to assess deeply the implication of Public Accounts Committee on performance of local government entities.

\section{Statement of Problem}

Though, PAC analyzed, provided recommendations and make follow upon the observations raised in audit report for each year end, yet some local entities were found not performing well due to either ineffective execution of recommendations provided with PAC or insufficient follow up of execution of recommendations.

This research was of great importance after finding that some recommendations provided by PAC are not reconsidered by some local administrative entities. For instance in 2015; the assessment done by PAC revealed that there was a transfers totaling Frw 2,025,748,886 that were made to Non Budget Agencies (NBAs) during the year were reported as expenditure in financial statements of the district, and yet reports from the Non Budget Agencies showed that these Non-Budget Agencies still had unutilized bank balances as at 30 June 2015; the bank statements and financial reports show that sectors had bank balances amounting to Frw 138,450,674 on sector respective bank accounts as at 30 June 2015. Therefore, the reported expenditure is overstated. In this context taking into account the provision of recommendation of PAC, an assessment of the status on the implementation of previous audit recommendations still revealed that most of previous recommendations were not implemented. Only 59\% were fully implemented and the remaining $41 \%$ are yet to be implemented [11].

In 2016, the report showed that, an assessment of the status on the implementation of previous audit recommendations still revealed that most of previous recommendations were not implemented. $21 \%$ of the recommendations were fully implemented, $18 \%$ were partially implemented and the remaining $61 \%$ are yet to be implemented [12]. In 2017, it was identified that an assessment of the status on the implementation of previous audit recommendations still revealed that most of previous recommendations were not implemented. $38 \%$ of the recommendations were fully implemented, $24 \%$ were partially implemented and the remaining 38\% are not yet implemented [13].

Regarding deputy auditor general opinion, the matters including; proper books of account have not been maintained and the financial statements do not give a true and fair view of the financial position of Nyamasheke district as at 30 June 2016, and of its financial performance and its cash flows for the year then ended in accordance with the guidelines provided by Ministerial Order $\mathrm{N}^{\circ} 001 / 16 / 10 / \mathrm{TC}$ of $26 / 01 / 2016$ relating to financial regulations and Organic Law $\mathrm{N}^{\circ} 12 / 2013 / \mathrm{OL}$ of 12/09/2013 on State Finances and Property [14].

However, it is within this context that the researcher wants to investigate the role of PAC in facilitating local administrative entities to perform well by giving recommendations and evaluate their implementation.

\section{Objectives of the Study}

This research followed the below specific objectives:

1. To assess the recommendations raised by PAC based OAG observations in Nyamasheke district.

2. To monitor and evaluate the progressive implementation of PAC and OAG recommendations in Nyamasheke district.

3. To weigh the indicators of performance at Nyamasheke district

4. To find out the correlation between the performance of Nyamasheke district and recommendations raised by PAC based OAG in Nyamasheke district. 


\section{Literature Review}

\subsection{Theoretical Framework}

\subsubsection{Conventional Wisdom Theory}

Conventional wisdom suggests that a strong legislature is built on a strong internal committee system, both in terms of committee powers and the willingness of members to engage in committee work. Committee assignments are the behavioral manifestation of legislative organization. Despite this, much remains unknown about how committee assignments happen and with what causes and consequences [3].

\subsubsection{Public Choice Theory and Organizational Practices}

According to John F. McEldowney [5], politics is an important behavioral process in organizational settings and the PAC is no exception. Under the public choice theory, the behavior of PAC members is presumed to be at two extremes, firstly, they are self-interested utility maximizers, motivated by factors like patronage, power, public reputation, and salaries. Secondly, PAC members may also be characterized as individuals who will work in the public interest; ensuring that laws and practice passed at SLA are working; having pride in their performance; and also, wishing to best serve the public. Hence, balancing their behavior along these two extremes will be a challenge to all PAC members. This theory was selected because it was linking the impact of PAC on performance of local entities.

The behavior of the PAC in dealing with its functions may have its roots in public choice theory and organizational practice. The PAC's appointment commences with the process of when a group of individuals win the election, and subsequently appointed as members of the SLA, with the majority winning party forming the government. Members of the SLA, whether from the ruling party or the opposition, may be appointed to sit on committees such as PAC. Some of the questions that come to mind are firstly, whether those elected and later appointed, delegated and trusted to administer and make decisions on behalf of the nation are competent, and secondly, whether an effective system of oversight and sanctions can be established for such individuals as a check and balance of their work. The rights that have been reserved for the general public to impose oversight function on the state government in avoidance of harm due to misuse of power and misconduct that may exists of government officials, must be reserved [5].

\subsubsection{Agency Theory}

Currently, there is a trend to enhance legislative involvement in the budget process in line with the postulation of agency theory. According to the proponents of agency theory, the principal should be able to hold the agent accountable. In the context of this research, the legislature represents the citizens' interests and therefore hold the government accountable for all public financial dealings. Being the representative of the citizens, the legislature carries out its works through various committees of national or state assembly. One of these committees is the PAC [9].

\subsection{Conceptual Framework}

Independent variable
Dependent Variable

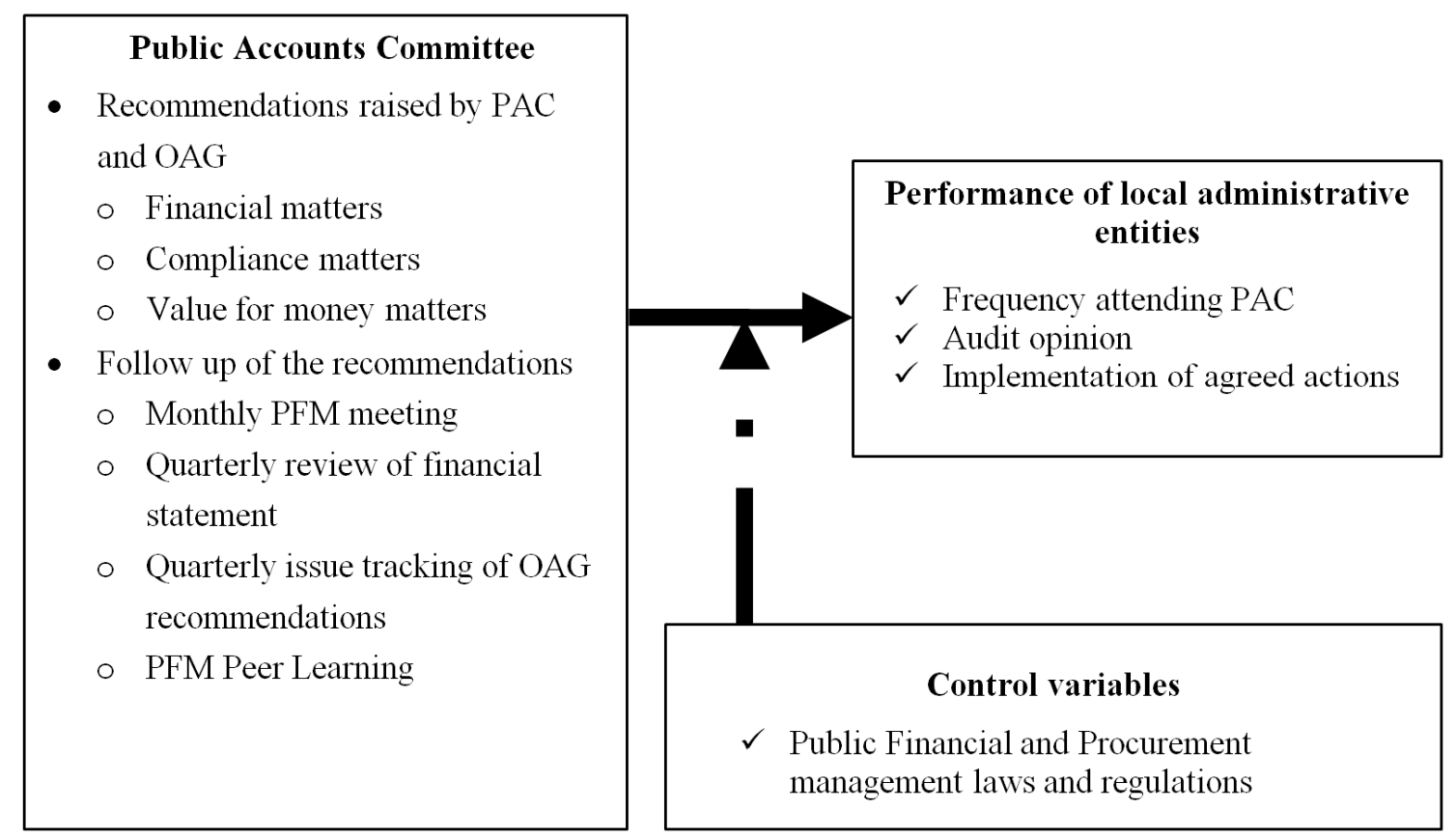

Source: Researcher conceptualization, 2019

Figure 1. Conceptual framework. 
The researcher considered and analyzed the independent variable which was public accounts committee putting into consideration recommendations and follow up raised by PAC in Nyamasheke district.

Normally, in recommendation, this study concentrated on how PAC take care about financial matters, compliance matters, value for money matters whereas to follow up, the researcher put in place to investigate how PAC follow ups are done; Monthly PFM meeting, quarterly review of financial statement, quarterly issue tracking of OAG recommendations and PFM Peer Learning.

Regarding independent variable which performance of local administrative, this study evaluated the frequency attending PAC, Audit opinion and how the implementation of agreed actions is executed in local administrative entities of Nyamasheke district.

For control variables, it was revealed that public financial and procurement management laws and regulations will help in giving the image of how the local administrative entities implemented PAC's recommendation through their performance.

\subsection{Empirical Studies}

Ibrahim UMAR [15] carried a study about Public Accounts Committee and Oversight Function in Nigeria: A Tower Built on Sinking Sand, where Public Accounts Committee of the National Assembly (PAC) is one of the highly empowered committees established by the standing orders of both houses to examine federal government (FGN) accounts showing the appropriation of the sums granted to meet the public expenditure and the auditor's report thereon. This study was carried out to probe the effectiveness of the committee's oversight function on audited reports of FGN to address the significant financial indiscipline and wastages of national resources in Nigeria public sector. The population of the study consists of 496 members of National Assembly, 29 Ministries and 5 Commissions. The sample size is made up of 150 staff selected at random. Structured questionnaire was used to elicit response and Z-test confirmed the hypothesis. The result reveals that PAC has not effectively exercise her oversight function due to late submission of audited reports by Auditor General of the Federation, weak regulatory framework and poor committee members' qualification and experience. The study recommended that: PAC members' appointment should be based on professional competence and cognate experience, regulatory framework should be overhauled and time frame for submission of financial and audited reports and PAC examination should be strictly in line with the 1999 constitution with punishment awarded for non-compliance [15].

On other hand, in the study carried out on performance and challenges of Public Accounts Committees (PAC) in Nigeria: A Case of Yobe State. This paper looks at the performance and challenges of PACs in ensuring public accountability. The study unpacks the effectiveness of PACs by identifying the key performance indicators. The study used documentary evidence, interviews and survey questions to elicit data from participant drawn from Yobe State House of Assembly. The data gathered were analyzed using content analysis. The findings of the study indicate apparent delays in tabling reports, complementation of the recommendation of PAC and the absence of disciplinary actions on erring MDAs. The low performance of the PAC was associated with the small size of the PAC, absence of opposition chairperson, inadequate supporting staffing and lack of awareness on the part of the general public. The study recommends the strengthening of the PAC by increasing the membership of the PAC, supporting staff and ensuring the presence of opposition members in the PAC [16].

In the study of Public Accounts Committees in eastern Africa: a comparative analysis whereby properly functioning Public Accounts Committees (PACs) are essential for promoting good governance, preventing misallocation of resources and curbing corruption. The purpose of the present paper is to analyze the organization, powers and the performance of East Africa's PACs so as to understand what they do, what makes them work well and what could make them work better. The analysis reveals that the Tanzania's PAC is the most active in the region because while it has fewer resources at its disposal than its Eastern African counterparts, it makes a more efficient use of the available resources as indicated by the fact that the Tanzanian PAC was able to carry out more oversight activities than the other PACs operating in the region in spite of having fewer resources. This evidence sustains the claim that legislators' political will is the single most important determinant of effective oversight. On the basis of the evidence presented in the paper, we formulate two policy recommendations: that in order to secure a more effective PAC performance, international organizations should pay greater attention to ensuring that legislators have the will to be effective overseers and that the Tanzania's PAC needs to be more adequately staffed and resourced [17].

\section{Research Methodology}

This study adopted descriptive cross sectional survey design. The target population in this study was the employees of Nyamasheke District with 23 employees were targeted from the head quarter in different department of management and in Council. The stratified sampling technique was used to select 23 of respondents. The information used in this research was originated from primary and secondary source while data collection techniques were questionnaire, interview and documentary techniques. Data were analyzed using both quantitative and qualitative technique and the results were presented by using the descriptive methods of data analysis.

\section{Data Analysis and Discussion}

\subsection{Recommendations Raised by PAC Basing on OAG Observations and How Are Being Implemented}

In this case, the researcher evaluated the recommendations raised by PAC based on OAG observations and how are being implemented. 
Table 1. Recommendations raised by PAC based on OAG observations and how are being implemented.

\begin{tabular}{|c|c|c|c|c|c|c|}
\hline Statement & $\begin{array}{l}\text { Strongly } \\
\text { agree }\end{array}$ & Agree & Disagree & $\begin{array}{l}\text { Strongly } \\
\text { disagree }\end{array}$ & Mean & $\begin{array}{l}\text { Std } \\
\text { deviation }\end{array}$ \\
\hline PAC involves in regular analysis of OAG report & $69.6 \%$ & $30.4 \%$ & $0 \%$ & $0 \%$ & 1.3043 & 0.47047 \\
\hline PAC provide with your recommendations to follow based on OAG observation & $52.2 \%$ & $47.8 \%$ & $0 \%$ & $0 \%$ & 1.4783 & 0.51075 \\
\hline Recommendations raised and provided by PAC are implemented & $65.2 \%$ & $34.8 \%$ & $0 \%$ & $0 \%$ & 1.3478 & 0.48698 \\
\hline PAC monitors the implementation of raised recommendations to local entities regularly & $47.8 \%$ & $52.2 \%$ & $0 \%$ & $0 \%$ & 1.5217 & 0.51075 \\
\hline PAC monitors the implementation of raised recommendations to local entities regularly & 60.9 & $39.1 \%$ & $0 \%$ & $0 \%$ & 1.3913 & 0.49901 \\
\hline Average & & & & & 1.40868 & 0.495592 \\
\hline
\end{tabular}

Source: Primary data, August, 2019

In table 1 the researcher sought to know the recommendations raised by PAC based on OAG observations and how are being implemented; in fact it was revealed that PAC involves in regular analysis of OAG report as strongly reported by $69.6 \%$ and agreed at $30.4 \%$ of respondents; $52.2 \%$ of respondents strongly agree and $47.8 \%$ agreed that PAC provided with recommendations to follow based on OAG observation, it was revealed that recommendations raised and provided by PAC are implemented as $65.2 \%$ of respondents strongly agreed and $34.8 \%$ agreed this situation, the respondents said again that PAC monitors the implementation of raised recommendations to local entities regularly as $47.8 \%$ of respondents strongly agreed and $52.2 \%$ agreed to this statement and finally to this case it was shown that PAC monitors the implementation of raised recommendations to local entities regularly as reported by $60.9 \%$ of respondents who are strongly agreed and $39.1 \%$ agreed. The overall mean was 1.41 and overall standard deviation was 0.4496 . The findings imply that the respondents agreed in general that recommendations raised by $\mathrm{PAC}$ based on $\mathrm{OAG}$ observations are being implemented.

\subsection{Time of Implementation of PAC Recommendations Based OAG Observation and How They Are Executed}

It necessary to evaluate the time of implementation of PAC recommendations based OAG observation and how they are executed.

Table 2. Time of implementation of PAC recommendations based $O A G$ observation and how they are executed.

\begin{tabular}{|c|c|c|c|c|c|c|}
\hline Statement & Strongly agree & Agree & Disagree & Strongly disagree & Mean & $\begin{array}{l}\text { Std } \\
\text { deviation }\end{array}$ \\
\hline Regular time to carry out monthly PFM meeting is planned & $69.6 \%$ & $30.4 \%$ & $0 \%$ & $0 \%$ & 1.3043 & 0.47047 \\
\hline PFM meeting help the execution of recommendation provided by PAC & $56.5 \%$ & $43.5 \%$ & $0 \%$ & $0 \%$ & 1.4348 & 0.506887 \\
\hline $\begin{array}{l}\text { Quarterly review of financial statement, Quarterly issue tracking of } \\
\text { OAG recommendations and PFM Peer Learning are analyzed. }\end{array}$ & $60.6 \%$ & $39.1 \%$ & $0 \%$ & $0 \%$ & 1.3913 & 0.49901 \\
\hline Recommendations raised by PAC are implemented & $52.2 \%$ & $47.8 \%$ & $0 \%$ & $0 \%$ & 1.4783 & 0.51075 \\
\hline The implementation of PAC recommendation is satisfactory & $26.1 \%$ & $73.9 \%$ & $0 \%$ & $0 \%$ & 1.7391 & 0.44898 \\
\hline
\end{tabular}

Source: Primary data, August, 2019

Table 2 shows the time of implementation of PAC recommendations based OAG observation and how they are executed; actually it was revealed that regular time to carry out monthly PFM meeting is planned as strongly reported by $69.6 \%$ and $30.4 \%$ of respondents agreed who agreed with this statement; $56.5 \%$ of respondents strongly agreed and 43.5 agreed that PFM meeting help the execution of recommendation provided by PAC, the Quarterly review of financial statement, Quarterly issue tracking of OAG recommendations and PFM Peer Learning are analyzed as $60.6 \%$ of the respondents strongly agreed and $39.1 \%$ agreed with this situation, it was reported that recommendations raised by PAC are implemented as it was pointed out by $52.2 \%$ of respondents who are strongly agreed and 47.8 agreed; further to this case again respondents said that the implementation of PAC recommendation is satisfactory as $26.1 \%$ of respondents strongly agreed to this whereby 73.9 agreed. The overall mean was 1.46956 and overall standard deviation was 0.487219 . The findings imply that the respondents agreed in general that there is a regular time of implementation of PAC recommendations based $\mathrm{OAG}$ observation and that they are executed.

\subsection{Indicators of Performance Among Local Administrative Entities}

It is necessary to evaluate indicators of performance among local administrative entities due to implementation of recommendations raised by PAC.

Table 3. Indicators of performance among local administrative entities.

\begin{tabular}{|c|c|c|c|c|c|c|}
\hline Statement & $\begin{array}{l}\text { Strongly } \\
\text { agree }\end{array}$ & Agree & Disagree & $\begin{array}{l}\text { Strongly } \\
\text { disagree }\end{array}$ & Mean & $\begin{array}{l}\text { Std } \\
\text { deviation }\end{array}$ \\
\hline $\begin{array}{l}\text { The district performed in, Social, health, agriculture, education, infrastructures and } \\
\text { other entities. }\end{array}$ & $65.2 \%$ & $34.8 \%$ & $0 \%$ & $0 \%$ & 1.3478 & 0.48698 \\
\hline Local entities performed efficiently due to PAC recommendations & $73.9 \%$ & $26.1 \%$ & $0 \%$ & $0 \%$ & 1.2609 & 0.44898 \\
\hline
\end{tabular}




\begin{tabular}{|c|c|c|c|c|c|c|}
\hline Statement & $\begin{array}{l}\text { Strongly } \\
\text { agree }\end{array}$ & Agree & Disagree & $\begin{array}{l}\text { Strongly } \\
\text { disagree }\end{array}$ & Mean & $\begin{array}{l}\text { Std } \\
\text { deviation }\end{array}$ \\
\hline $\begin{array}{l}\text { Financial matters, Compliance matters are encountered and resolved due to PAC } \\
\text { recommendations }\end{array}$ & $73.9 \%$ & $26.1 \%$ & $0 \%$ & $0 \%$ & 1.2609 & 0.44898 \\
\hline $\begin{array}{l}\text { Value for money matters are encountered and resolved due to PAC recommendations } \\
\text { Average }\end{array}$ & $65.2 \%$ & $34.8 \%$ & $0 \%$ & $0 \%$ & $\begin{array}{l}1.3478 \\
1.29566\end{array}$ & $\begin{array}{l}0.48698 \\
0.458732\end{array}$ \\
\hline
\end{tabular}

Source: Primary data, August, 2019

Table 3 shows the indicators of performance among local administrative entities due to implementation of recommendation raised by PAC; actually it was revealed that the district performed in, Social, Health, Agriculture, Education, Infrastructures and other entities as reported by $65.2 \%$ of respondent who strongly agreed and $34.8 \%$ agreed with this statement; $78.3 \%$ of respondents strongly pointed out that local administrative entities executed PAC recommendations and 21.7 agreed, actually local entities performed efficiently due to PAC recommendations as strongly reported by $73.9 \%$ of respondents and $26.1 \%$ agreed to this situation, $73.9 \%$ of respondents strongly agreed and $26.1 \%$ agreed that Financial matters, Compliance matters are encountered and resolved due to PAC recommendations and Value for money matters are encountered and resolved due to PAC recommendations as $65.2 \%$ of respondents strongly agreed and $34.8 \%$ agreed with this situation. The overall mean was 1.29566 and overall standard deviation was 0.458732 . The findings imply that the respondents agreed in general that the local entities in study area performed due to implementation of PAC recommendations.

\subsection{Overall Regression Analysis}

The findings were analyzed using regression analysis ANOVA and regression of coefficient to evaluate whether PAC have impact on performance of local administration entities.

\subsubsection{Regression Analysis}

Table 4 shows the fitness of the regression model in explaining the variables under the study. The findings show that the predictor variables; Recommendation raised by PAC and Follow up of recommendations explained the performance of local entities in Nyamasheke district. $\mathrm{R}$ square of $0.787(78.7 \%)$ supported the findings. This implies that the predictor variables (Recommendations raised by PAC and follow up of recommendations) can explain the performance of local administrative entities at $78.7 \%$ and the remaining $21.3 \%$ are explained by other variable which were not studied in this research and the researcher recommend that that they could be put into consideration in future studies.

Table 4. Model of performance of local administrative entities/ Recommendations raised by PAC; Follow up of the recommendations.

\begin{tabular}{llll}
\hline Model & R & R Square & Adjusted R Square \\
\hline 1 & $.887^{\text {a }}$ & .787 & .766 \\
\hline
\end{tabular}

a. Predictors: (Constant), Recommendations raised by PAC_Follow up of recommendations

\subsubsection{Analysis of Variance}

A null hypothesis was formulated saying that there is no statistical significance between the PAC practices and financial performance of Local Administrative Entities. The table below clearly indicates the result of the study.

Table 5. Analysis of variance (ANOVA).

\begin{tabular}{llllll}
\hline Model & & Sum of Squares & df & Mean Square & F \\
\hline \multirow{2}{*}{1} & Regression & 3.490 & 2 & 1.745 & 36.957 \\
& Residual & .944 & 20 & .047 & $.000^{\mathrm{b}}$ \\
& Total & 4.435 & 22 & & \\
\hline
\end{tabular}

a. Dependent Variable: Performance of local administrative entities

b. Predictors: (Constant), Recommendations_raised_by_PAC_Follow_up_of_recommendations

Table 5 presented ANOVA statistics which indicates that the overall model was statistically significant. Probability (p) value of 0.000 supported this. The reported $\mathrm{p}$ was significant in this study because it was less than the conventional probability of 0.05 significance level. These results indicate that recommendations raised by PAC and Follow up of recommendations are good predictors of performance of local administrative entities.

\subsubsection{Regression Coefficients}

Table 6. Regression of coefficient.

\begin{tabular}{|c|c|c|c|c|c|c|}
\hline \multirow{2}{*}{\multicolumn{2}{|c|}{ Model }} & \multicolumn{2}{|c|}{ Unstandardized Coefficients } & \multirow{2}{*}{$\begin{array}{l}\text { Standardized Coefficients } \\
\text { Beta }\end{array}$} & \multirow{2}{*}{$\mathbf{t}$} & \multirow{2}{*}{ Sig. } \\
\hline & & B & Std. Error & & & \\
\hline \multirow{3}{*}{1} & (Constant) & .111 & .149 & & 6.744 & .465 \\
\hline & Recommendation_raised_by_PAC & .472 & .156 & .408 & 3.031 & .007 \\
\hline & Follow up and implementation of recommendations & .472 & .112 & .569 & 4.230 & .000 \\
\hline
\end{tabular}

a. Dependent Variable: Financial performance of local administrative entities 
The results shown in table 6 above indicated that the follow up and implementation of recommendations raised by PAC have a significant positive influence on financial performance of local administrative entities. This is shown by the regression analysis value of $\mathrm{t}$ - calculated which is greater than 2 (i.e 6.744) and $\mathrm{P}$ Value is 0.465 at $95 \%$ level of significance that is less than $5 \%$.

The study used the formula of $Y s=\beta_{0}+\beta_{1} X_{1}+\beta_{2} X_{2}+\varepsilon$ whereby $Y s$ is the dependent variable indicator which is "performance of local administrative entities" and independent variable factors $\left(\mathrm{X}_{1} \& \mathrm{X}_{2}\right)$ which are "recommendations raised by $\mathrm{PAC}$ and follow up and implementation of recommendations" and lastly $\varepsilon$ represents standard errors.

As explained by the linear regression equation, it is clear that one unit change of $X_{1}$ and $X_{2}$, lead to change times 0.408 and 0.569 of the recommendations raised by PAC and their related implementation respectively. In the other case if all independent variable indicators are zero, the dependent variable equals to the constant (0.111).

Thus, according to the results indicated to the table 6 , there is positive relationship between recommendations raised by PAC and follow up and implementation of recommendations to performance of local administrative entities. Thus, when Nyamasheke district adopted PAC recommendations only without taking into consideration other factor, result on the performance became $\mathrm{Ys}_{\mathrm{s}}=.111+.408 \mathrm{X}_{1}+\varepsilon$; Therefore, when Nyamasheke district used only follow up of recommendation, the performance was becoming $\mathrm{Ys}_{\mathrm{s}}=.111+.569 \mathrm{X}_{2}+\varepsilon$.

\section{Conclusion and Recommendations}

This study was interested on the implication of PAC on performance of local administrative entities in study area, actually the motivation for this research was that PAC contribute in giving and following up the recommendation about compliance matters, value for money matters and other related local administrative entities evaluation. The objectives of this study were; to assess the recommendations raised by PAC based OAG observations in study area, to monitor and evaluate the progressive implementation of PAC and $\mathrm{OAG}$ recommendation, to weigh the indicators of performance in study area and to find out the correlation between the performance and recommendations raised by PAC based OAG in study area.

By conclusion, it is clear from study area that PAC contributes in performance of local administrative entities found in study area. Normally, they have expanded and managed their daily operations and made effective decisions. Actually, they have moved from situations of multiple problems, particularly financial matters, compliance matters and value for money matters, to seeing themselves as viable in performance. They feel more secure because they can meet their effective daily operations and decision making. However, they are still facing some challenges in the integration of PAC recommendations in performance of their daily operations and once they are mitigated with proposed strategies the performance will be effectively increased.

The followings are proposed recommendations that need to be implemented in order to ensure that the local administrative entities are financially performing well:

Carrying out regular monthly public financial management meeting, quick intervention of the decision makers about the persisting issue not yet implemented, refresher training for all PFM cycle staff, should continuously capacitate PACs members and support staff on effective oversight, this can be done through training, professional skills development programs (recognized qualification), exchange programs, and study opportunities, unless there is underperformance, members and support staff of PACs must remain in the same Committee in order to build institutional memory and for easy tracking of resolutions.

\section{References}

[1] APAC Annual Report (2008/09). association of public accounts committees. Cape Town, South Africa, pp. 60. https://www.academia.edu/18999793/associationof_Public_A ccounts_Committee

[2] Auditor-General of South Africa (2009/10). Limpopo SCOPA briefing. PFMA audit outcomes for the 2009/10 financial year. Retried on 18 August 2011 at https://www.gov.za/sites/default/files/gcis_document/201409/ auditor-general-annual-report-09-10-final0.pdf

[3] Burnell, P. (2001). Financial indiscipline in Zambia's Third Republic. The role of parliamentary scrutiny", legislative studies Vol. 7 No. 3, pp. 34-64.

[4] Beauchamp, C. (1990). National Audit Office: Its role in privatization. public money and management, summer, 55-8 at 57.

[5] John F. McEldowney, School of Law. (2004). Accountability and the public accounts committee. Lessons in parliamentary oversight - the United Kingdom experience. University of Warwick, England.

[6] McGee, David. (2002). The Overseers - Public accounts committees and public spending, Pluto Press, London.

[7] NAO (1999), Helping the Nation Spend Wisely Annual Report. See A Framework for Value for Money Audits (National Audit Office) Cmnd 9755.

[8] Hedger, E. and Blick, A. (2008). Enhancing accountability for the use of public sector resources: How to improve the effectiveness of Public Accounts Committees, London: Overseas Development Institute.

[9] McGee, D. (2002). The Overseers: Public Accounts Committees and public spending, London: Pluto Press.

[10] Kan-Dapaah, A. (2011). Public accountability effects and donor budget support, paper presented at the $6^{\text {th }} \mathrm{CDD} / \mathrm{FNF}$ Annual Liberal Lecture.

[11] Nyamasheke district audit report for fiscal year 2014/2015.

[12] Nyamasheke district audit report for fiscal year 2015/2016. 
[13] Nyamasheke district audit report for fiscal year 2016/2017.

[14] Nyamasheke district audit report for fiscal year 2017/2018.

[15] Ibrahim UMAR (2017). Performance and challenges of Public Accounts Committees (PAC). International Journal Yobe State University. Nigeria, from https://www.researchgate.net/publication/330002663_The per formance_and_challenges_of_Public_Accounts_Committees PAC in Nigeria A Case of Yobe State
[16] Ogbanu (1991). Public Accounts Committee and oversight function in Nigeria: A tower built on sinking sand Retrieved at https://papers.ssrn.com/sol3/papers.cfm?abstract_id=2426199

[17] Riccardo Pelizzo and Abel Kinyondo (2014). Public Accounts Committees in Eastern Africa: a comparative analysis, USA. 